\title{
Comparative Study of the Effects of Drying Methods on Antioxidant Activity of Dried Strawberry (Fragaria Var. Camarosa)
}

\author{
Maritza Alonzo-Macías ${ }^{1,2}$, Anaberta Cardador-Martínez ${ }^{1}$, Sabah Mounir ${ }^{2,3}$, \\ Gerardo Montejano-Gaitán ${ }^{1} \&$ Karim Allaf $^{2}$ \\ ${ }^{1}$ Instituto Tecnológico y de Estudios Superiores de Monterrey, Campus Querétaro. Avenida Epigmenio González \\ No. 500 Fraccionamiento San Pablo, Querétaro, Qro., México \\ ${ }^{2}$ University of La Rochelle, Pole Science and Technology, Laboratory of Engineering Science for Environment \\ (LaSIEFRE 3474CNRS), Avenue Michel Crépeau, La Rochelle, France \\ ${ }^{3}$ Food Science Department, Faculty of Agriculture, Zagazig University, Egypt \\ Correspondence: Karim Allaf, University of La Rochelle, Pole Science and Technology, Laboratory of \\ Engineering Science for Environment (LaSIEFRE 3474CNRS), Avenue Michel Crépeau, La Rochelle 17042, \\ France. E-mail: kallaf@univ-lr.fr
}

\author{
Received: January 5, 2013 Accepted: February 12, 2013 Online Published: March 27, 2013 \\ doi:10.5539/jfr.v2n2p92 URL: http://dx.doi.org/10.5539/jfr.v2n2p92
}

\begin{abstract}
Hot air drying (HAD), freeze-drying (FD), and swell-drying (SD, coupling instant controlled pressure drop, DIC, to standard hot air) were applied to strawberries (Fragaria var. Camarosa). The total phenol, total flavonoid, and total anthocyanin contentswere evaluated versusthe drying methods. The correlations between the bioactive compounds and antioxidant activity were investigated. The obtained results showed that the differences in phenol levels were no quite comparing the three drying techniques; however, great variations were reported for anthocyanin and flavonoid content.

A strong correlation between the antioxidant activity and anthocyanin content was found in SD strawberries. Also, it was observed that saturated steam pressure (P) of DIC texturing operation, had a significant effect on the studied parameters compared to the thermal holding time (t). The optimum conditions of DIC were $\mathrm{P}=0.35$ MPa for $\mathrm{t}=10 \mathrm{~s}$ to obtain the highest levels of phenols, flavonoids, and anthocyanins, as well as antioxidant activity.
\end{abstract}

Keywords: antioxidant activity, anthocyanins, phenolic compounds, instant controlled pressure drop, drying, strawberry

\section{Introduction}

The health benefits resulting from the use of natural products rich in bioactive substances have promoted a growing interest from pharmaceutical, food and cosmetic industries. Strawberries are really attractive by their red color, excellent taste and as source of bioactive phenolic compounds including hydroxycinnamic acids, ellagic acid, ellagitannins, flavan-3-ols, flavonols and anthocyanins (Giampieri et al., 2012; Oszmiański, Wojdyło, \& Kolniak, 2009). Moreover, strawberries are economically and commercially important and widely consumed fresh or in processed forms, such as jams, juices, and jellies by their sweet taste and potential benefits to the health (Giampieri et al., 2012). And, by their antioxidant activity, they are important in the prevention of certain types of cancers, as well as, anti-inflammatory functions, cardiovascular, obesity and other chronic diseases (Basu et al., 2009; Crecente-Campo, Nunes-Damaceno, Romero-Rodríguez, \& Vázquez-Odériz, 2012; Giampieri et al., 2012; Hannum, 2004; Olsson et al., 2004; Oszmiański et al., 2009). It is established that oxidation processes are involved in various chronic and degenerative diseases and that the intake of chemical constituents with antioxidant activity, found in plants in high concentrations, has beneficial effects on health. Phenolic compounds and anthocyanins, two large and heterogeneous groups of biologically active molecules, are known to be dietary components in fruits and vegetables with antioxidant activities (Panico et al., 2009). Phenolic compounds present in strawberries are ellagic and $p$-coumaric acid; flavonoids as quercetin, kaempferol and myricetin. Anthocyanins are a group of phenolic compounds responsible for the red-blue color of many fruits and vegetables. Pelargonidin 3-glucoside, cyaniding 3-glucoside and pelargonidin 3-rutinoside are the 
main anthocyanins found in strawberries, which are responsible for their bright red color (Böhm, 1994; Crecente-Campo et al., 2012). These bioactive compounds are of prominent importance; in fact, anthocyanin pigments constitute an integral part of the sensory attributes and contribute directly to the coloration of the strawberries. Anthocyanins were claimed to possess diverse biological properties and therefore, they are considered as the main secondary metabolites with a potential nutritional value. In vitro oxidation assays showed that the antioxidant activity of strawberries has been directly correlated with anthocyanin content in the fruit (Andersen, Fossen, Torskangerpoll, Fossen, \& Hauge, 2004). However, this content is affected by the cultivar, ripening stage, storage conditions and their post-harvest treatment (Crecente-Campo et al., 2012; Olsson et al., 2004).

Unfortunately, strawberries postharvest life is relatively short, due to their highly fragile structure and their high rates of respiration (Modise, 2008). At the same time, they are highly susceptible to bruises and fungal attacks (Blanda et al., 2009). This problem affects also their bioactive compounds.

To extent their shelf life and preserve their bioactive compounds, technologies as hot air drying and freeze-drying were used. Comparing the two processes, freeze-drying is the best method applied in the industry to preserve high-value foods such as coffee, spices, food ingredients and strawberries; however, as it is costly and time consuming process, its applications or uses are limited to high value foods and pharmaceutics (Ratti, 2001). On the other hand, hot air drying is considered as the most ancient process used to preserve foods; it offers dehydrated products that have an extended life, up to a year but, unfortunately, the quality of a conventionally dried product is usually drastically reduced compared to the original foodstuff.

Thus, new trends in drying process are used to improve the quality of dried foods and preserve their nutraceutical value. New technologies, such as swell-drying "SD"; Instant Controlled Pressure Drop DIC-assisted hot air drying; can improve the process performances, and the quality attributes of dried foods such as strawberries. SD is revealed by many authors (Albitar, Mounir, Besombes, \& Allaf, 2011; Haddad \& Allaf, 2007; Kamal, Sobolik, Kristiawan, Mounir, \& Allaf, 2008; Louka \& Allaf, 2004; Sabah Mounir, Allaf, Mujumdar, \& Allaf, 2012; S. Mounir, Besombes, Al-Bitar, \& Allaf, 2011).Their work reviewed the effect of DIC on the quality attributes of dried food products and on drying process performance. Furthermore, the SD is largely used at industrial scale to produce swell-dried products (ABCAR-DIC Process, La Rochelle, France).

DIC is a high temperature-short time (HTST) treatment followed by an abrupt pressure drop towards a vacuumcrossing the glass transition boundary: the pressure dropping induces an abrupt cooling of treated product preserving the expanded state of the new obtained structure (Sabah Mounir et al., 2012).

The aim of this study was to compare three processes of drying; swell-drying (SD), freeze-drying (FD), and classical hot air drying (HAD) in terms of quality attributes, including total phenolic content, flavonoid content, total anthocyanin content and the antioxidant activity of dried strawberries.

\section{Materials and Methods}

\subsection{Chemicals and Reagents}

Gallic acid; Rutin; pelargonidin-3-glucoside; 2,2-Diphenyl-1-picrylhydrazyl (DPPH); cyaniding-3-glucoside, and Trolox (6-hydroxy-2,5,7,8-tetramethylchroman-2-carboxylicacid), which is a hydrophilic analogue of vitamin E; were purchased from Sigma Chemical Co., St. Louis, MO, USA. Ethanol and methanol were purchased from J.T. Baker (Deventer, The Netherlands). All other reagents and chemicals of analytical grade were procured from local sources (Queretaro, Mexico) and milli-Q water was used.

\subsection{Biological Material}

The strawberries (Fragaria var. Camarosa) were purchased from Carrefour (La Rochelle, France). They were immediately transported to the laboratory and stored at $5^{\circ} \mathrm{C}$ until the next day. Strawberries were sorted, washed with tap water and cut with kitchen knife into slices of $4-5 \mathrm{~mm}$ as thickness. After that, the total quantity was divided in three batches; one for each process; hot air drying (HAD), freeze-drying (FD) and swell-drying (SD).

\subsection{Water Content}

Water content was determined according toa slightly modified Karathanos method (1999). Moisture of all dried strawberries were quantified gravimetrically in triplicate by drying $2.5 \pm 0.1 \mathrm{~g}$ of samples in a laboratory drying oven (UFE 400 Memmert, Schwabach, Germany), at $65^{\circ} \mathrm{C}$ during $48 \mathrm{~h}$. The water content (W) in dry basis (\%db), of samples was calculated according to the following Equation 1: 


$$
\mathrm{W}_{d b}=\frac{\mathrm{m}_{\mathrm{i}}-\mathrm{m}_{\mathrm{d}}}{\mathrm{m}_{\mathrm{d}}} \%
$$

Where: $\mathrm{m}_{\mathrm{i}}$ and $\mathrm{m}_{\mathrm{d}}$ are strawberry mass $(\mathrm{g})$ before and after complete drying, respectively.

\subsection{Dehydration Techniques}

\subsubsection{Hot air Drying (HAD)}

Strawberries slices were dried in hot air drier (Memmert: Universal Oven UNB Model 800, Schwabach, Germany) at $50^{\circ} \mathrm{C}$. The initial partial pressure of vapor in the air was $265 \mathrm{~Pa}$ with an air flux of $1.2 \mathrm{~m} / \mathrm{s}$. Slices were dried until attaining $3.0 \%$ of water content $(\mathrm{db})$. The total time of drying was about 24 hours. These samples were recorded as (HAD).

\subsubsection{Freeze-Drying (FD)}

A freeze-drying equipment (model: RP2V, Serail, France) was used to freeze-dry the strawberry slices. The strawberry samples were frozen outside from the freeze-dryer at $-20^{\circ} \mathrm{C} / 2 \mathrm{~h}$, the frozen samples were transferred immediately to the freeze-drying system to carry out their drying; sublimation $\left(-20^{\circ} \mathrm{C}, 0.66 \mathrm{~Pa} / 12 \mathrm{~h}\right)$ and desorption $\left(25^{\circ} \mathrm{C}, 0.66 \mathrm{~Pa} / 12 \mathrm{~h}\right)$. The freeze-dried samples were packed in airtight bags and stored until their assessments. These samples were recorded as (FD).

\subsubsection{Swell-Drying (SD)}

As previously mentioned, swell-drying is a DIC-assisted classical hot air drying. Thus, strawberry samples were partially hot air dried at $50^{\circ} \mathrm{C}$ (Memmert: Universal Oven UNB Model 800, Schwabach, Germany) until a water content of $18 \% \mathrm{db}$ was attained. The initial partial pressure of vapor in the air was $265 \mathrm{~Pa}$ with an air flux of 1.2 $\mathrm{m} / \mathrm{s}$. This step needed about 8 h (Alonzo-Macías, Mounir, Cardador-Martínez, Montejano-Gaitán, \& Allaf, 2012).

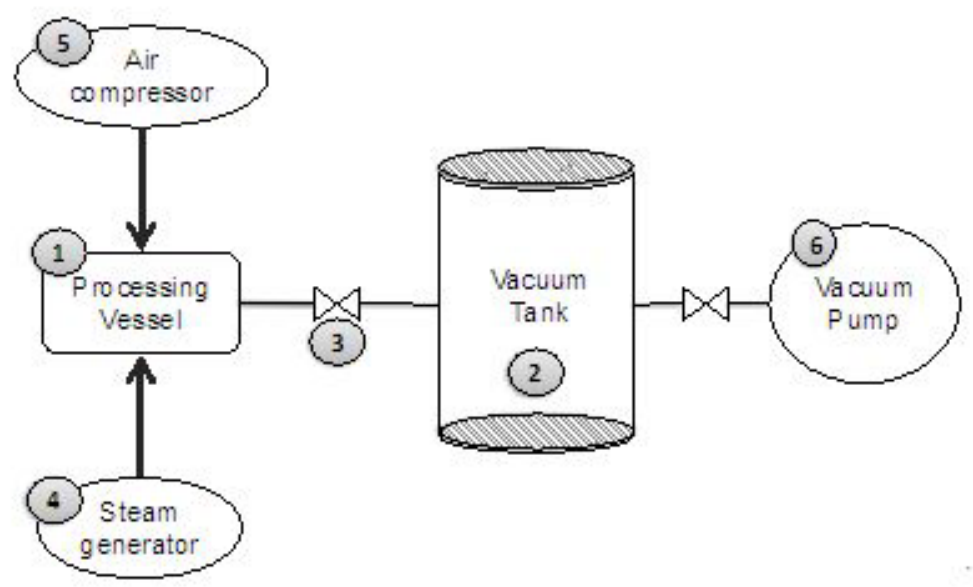

Figure 1. Schematic diagram of the DIC reactor

1: Processing vessel; 2: Vacuum tank; 3: Abrupt opening valve; 4: Steam generator; 5: Air compressor 6: Vacuum pump.It can be briefly described as followed: $\boldsymbol{A}$ ) The processing vessel, where samples are placed and treated. $\boldsymbol{B})$ The vacuum system, which consists mainly of a vacuum tank with a volume 130 times greater than the processing vessel, andan adequate vacuum pump. The initial vacuum level was almost maintained at $5 \mathrm{kPa}$ in all the experiments. $C$ ) A pneumatic valve that ensures the connection/disconnection between the vacuum tank and the processing vessel inducing the abrupt pressure dropping within less than $0.2 \mathrm{~s}(\Delta \mathrm{P} / \Delta \mathrm{t}>0.5 \mathrm{MPa} / \mathrm{s})$. DIC reactor has been largely described in many scientific papers (Ben Amor \& Allaf, 2009; Haddad \& Allaf, 2007; Louka \& Allaf, 2004; Sabah Mounir et al., 2012).

The samples were stored in a cold room at $5^{\circ} \mathrm{C}$ for $24 \mathrm{~h}$ within airtight bags in order to homogenize the sample water content. Subsequently, the partial hot air dried strawberries were treated in a DIC-reactor (Figure 1) according to the experimental design (Table 2). Finally, after DIC treatment, the treated samples were dried under the same conditions of the hot air drying before the DIC treatment, but this step needed only $1 \mathrm{~h}$ to attain a suitable level of water content for storage, about $3.0 \% \mathrm{db}$. These samples were recorded as (SD). 


\subsection{Samples Extraction}

The different strawberry samples $(0.5 \mathrm{~g})$ were weighted in a $30 \mathrm{~mL}$ centrifuge tube, and $10 \mathrm{~mL}$ of acidified methanol $(1.0 \% \mathrm{HCl}$ in methanol, $\mathrm{v} / \mathrm{v})$ were added and agitated for $2 \mathrm{~h}$ at room temperature in darkness. The sample suspensions were centrifuged at $6000 \mathrm{rpm}$ for $10 \mathrm{~min}$ at $4^{\circ} \mathrm{C}$ and the supernatants were stored at $-20^{\circ} \mathrm{C}$ until analysis, the operation was performed in duplicate.

\subsubsection{Total Phenoliccontent}

Total phenolic content was estimated by using the Folin-Ciocalteu colorimetric method (Singleton, Orthofer, \& Lamuela-Raventós, 1999). Briefly, $0.02 \mathrm{~mL}$ of the extracts was oxidized with $0.1 \mathrm{~mL}$ of $0.5 \mathrm{~N}$ Folin-Ciocalteureagent, and then the reaction was neutralized with $0.3 \mathrm{~mL}$ sodium carbonate solution $(20 \%)$. The absorbance values were obtained by the resulting blue color measured at $760 \mathrm{~nm}$ with a Spectrophotometer (UV-Vis Double Beam UVD-3500, Labomed, Inc. USA) after incubation for $2 \mathrm{~h}$ at $25^{\circ} \mathrm{C}$. Quantification was achieved on the basis of a standard curve of Gallic acid from 0 to $500 \mu \mathrm{g} / \mathrm{mL}$. Results were expressed as mg of Gallic acid per $\mathrm{g}$ of dry weight (mg eq. GA/g db).

\subsubsection{Flavonoid Content}

The spectrophotometric assay for the quantitative determination of flavonoid content was determined according toOomah, Cardador-Martínez, and Loarca-Piña (2005). Briefly, the method consisted of mixing $50 \mu \mathrm{L}$ of the methanolic extract with $180 \mu \mathrm{L}$ of distilled water and $20 \mu \mathrm{L}$ of a solution of $10 \mathrm{~g} / \mathrm{L}$ 2-aminoethyldiphenylborate in a 96-well microtitration flat-bottom plate. The absorbance of the solution was monitored at $404 \mathrm{~nm}$ with a spectrophotometer (xMark Microplate Spectrophotometer, BioRad, Japan). Extract absorption was compared with a Rutin standard at different concentrations ranging from 0 to $200 \mu \mathrm{g} / \mathrm{mL}$. Flavonoids content was expressed as mg Rutinperg of dry weight (mg eq. Rutin/g db).

\subsubsection{Total Anthocyanincontent}

$0.2 \mathrm{~mL}$ of extract was diluted with $1.8 \mathrm{~mL}$ acidified methanol $(1.0 \% \mathrm{HCl}$ in methanol) and absorbance was taken at $250 \mathrm{~nm}$ (Spectro UV-Vis Double Beam. UVD-3500 Labomed, Inc. USA). An acid pH was used to take the anthocyanins to the flavylium ion form, which exhibits coloration, thus to be able to quantify them by spectrophotometry. Total anthocyanins concentration (TAC) was calculated as pelargonidin-3-glucosideaccording to the Equation 2 (Abdel-Aal \& Hucl, 1999):

$$
\boldsymbol{T A C}=\left(\frac{A}{\varepsilon}\right)\left(\frac{V o l}{1000}\right)(M W)\left(\frac{1}{\text { sampleweight }}\right) 10^{6}
$$

Where:

TAC: concentration of total anthocyanin content per sample were expressed as mg pelargonidin-3-glucoside equivalent per $\mathrm{g}$ of dry weight (mg eq. Pe-3-Gl/g db)

A: absorbance reading,

$\varepsilon$ : molarabsorptivity (pelargonidin-3-glucoside $=15,600 \mathrm{~L} /(\mathrm{mol} \mathrm{cm})$ ),

Vol: total volume of anthocyanin extract, and

MW: molecular weight of pelargonidin-3-glucoside $=433.2 \mathrm{~g} / \mathrm{mol}$

\subsubsection{Determination of Anthocyanins by HPLC}

Strawberry extracts were filtered through a $0.45 \mu \mathrm{M}$ nylon membrane-filter. HPLC analysis was performed using Agilent 1200 HPLC system (Agilent Technology 1200 series, Palo Alto, CA), equipped with quaternary pumps, autosampler and a diode array detector. Anthocyanin separation were performed using an Eclipse XDB-C18 column $(5 \mu \mathrm{M}, 4.6 \mathrm{~mm} ; 150 \mathrm{~mm})$ at $28^{\circ} \mathrm{C}$. Mobile phases were constituted of $1.0 \%$ methanol acidified (A) and $5.0 \%$ formic acid (B) at a flow rate of $1 \mathrm{~mL} / \mathrm{min}$. The gradient condition started with $20 \% \mathrm{~A}$, linearly increased to $85 \% \mathrm{~A}$ at $10 \mathrm{~min}$, finally it decreased to $20 \% \mathrm{~A}$ at $15 \mathrm{~min}$. Calibration curves $(0-1 \mathrm{mg} / \mathrm{mL})$ were realized to quantify cyanidin-3-glucoside (Cy-3-Gl, mg/g db) and pelargonidin-3-glucoside (Pe-3-Gl, mg/g db).

\subsubsection{Determination of Antioxidant Capacity by DPPH Method}

Measurement of antioxidant capacity was carried out using 2,2-Diphenyl-1-picrylhydrazyl (DPPH) as a free radical. Reduction of DPPH by an antioxidant or a free radical produces decreased absorbance at $515 \mathrm{~nm} .20 \mu \mathrm{L}$ of the extract were mixed with $200 \mu \mathrm{L}$ DPPH (125 $\mu \mathrm{M}$ in $80 \%$ methanol). After $90 \mathrm{~min}$, the plate was read at $520 \mathrm{~nm}$ in a spectrophotometer and the antioxidant capacitywas calculated as a percentage of DPPH discoloration according toBurda and Oleszek (2001). The analysis was performed in triplicate. 


\subsection{DIC Experimental Design}

The operating parameters of DIC treatment in this study were only the saturated steam pressure (MPa) and the thermal holding time (s), while the initial water content (W) of strawberries was maintained constant at $18 \% \mathrm{db}$. Hence, in order to study these parameterson the various response parameters (total phenolic content, flavonoid content, total anthocyanin content, pelargonidin-3-glucoside, cyanidin-3-glucoside and antioxidant activity), a central composite rotatable design was used (Statgraphics, Centurion XV, USA) (Table 1). For the 2 factors, the design resulted in 11 trials; $4\left(2^{2}\right)$ factorial points, 4 axial points to form a central composite design, and 3 center points for replications (Table 2). The ranges and the center point (Table 1) were defined after preliminary trials The 11 trials were run in random order to minimize the effects of unexpected variability on observed responses due to external factors. The mathematical empirical model applied in this study was:

$$
Y=\beta_{0}+\sum_{i=1}^{n} \beta_{i} \chi_{i}+\sum_{i=1}^{n} \beta_{i i} \chi_{i}^{2}+\sum_{i=1}^{n-1} \sum_{j=2}^{n} \beta_{i j} \chi_{i} \chi_{j}+\varepsilon
$$

Where:

$\mathrm{Y}$ : the response, $\beta_{\mathrm{i}}, \beta_{\mathrm{ii}}, \beta_{\mathrm{ij}}$ : the regression coefficients, $\mathrm{X}_{\mathrm{i}}$ and $\mathrm{X}_{\mathrm{j}}$ : the independent variables, $\varepsilon$ :random error, and $\mathrm{i}$ and $\mathrm{j}$ : the indices of the factors.

For more understanding and interpreting the results,

- The analysis of variance (ANOVA) was used to determine significant differences between independent variables $(\mathrm{p}<0.05)$;

- Pareto chart was used to identify the impact of variables on various responses. The vertical line in the Pareto chart determines the effects that are statistically significant at the $95 \%$ confidence level;

- Surface response methodology plots to optimize the various responses;

- General trends to analyze various responses behavior in front of variable changes;

- Empirical model coefficients to determine the regression model for each response and $\mathrm{R}^{2}$ to accurate fitting models to real data.

Table 1. Coded and real ranges of independent variables used in the 2-variable 5-level rotatable experimental design

\begin{tabular}{lccccc}
\hline Factor(Coded Level) & $-\alpha$ & -1 & 0 & 1 & $+\alpha$ \\
Processing pressure (MPa) & 0.10 & 0.19 & 0.35 & 0.53 & 0.60 \\
Processing time (s) & 10 & 13 & 20 & 27 & 30 \\
\hline
\end{tabular}

$\alpha($ axial distance $)=\sqrt[4]{\mathbf{2}^{k}}, \mathrm{k}$ is the number of experiments of orthogonal desig. In this case, $\mathrm{k}=2$ and $\alpha=1.4142$.

Table 2. Trials in the experimental design for DIC process

\begin{tabular}{lccccccccccc}
\hline & \multicolumn{11}{c}{ DIC } \\
\hline Run & $\mathbf{1}$ & $\mathbf{2}$ & $\mathbf{3}$ & $\mathbf{4}$ & $\mathbf{5}$ & $\mathbf{6}$ & $\mathbf{7}$ & $\mathbf{8}$ & $\mathbf{9}$ & $\mathbf{1 0}$ & $\mathbf{1 1}$ \\
Pressure, $\mathbf{P}$ (MPa) & 0.60 & 0.35 & 0.35 & 0.53 & 0.53 & 0.35 & 0.17 & 0.17 & 0.10 & 0.35 & 0.35 \\
Time, t (s) & 20 & 30 & 20 & 27 & 13 & 20 & 13 & 27 & 20 & 10 & 20 \\
\hline
\end{tabular}

\section{Results and Discussion}

The present study was carried out to evaluate the antioxidant capacity, total phenolic, total flavonoid, and total anthocyanin contents in strawberries samples dried by different techniques. Hence, the discussion and the interpretation of the results are presented in two parts; a comparison between the different drying techniques (HAD, FD and SD) and, on the other hand, a study of operating parameters of DIC treatment in order to optimize the texturing operation within SDin the light of obtained results. 


\subsection{Total Phenolic Content}

Table 3 shows the total phenolic content (TPC) in different dried strawberries. The TPC were not quite different in the studied drying methods. The TPC in HAD, FD and SD (DIC10, 0.35 MPa and $10 \mathrm{~s}$ ) were 16.18, 18.41, and $14.47 \mathrm{mg}$ eq.GA/g db, respectively. The TPC in FD samples was higher than those in HAD and SD by $12 \%$ and $21 \%$, respectively, and TPC in SD samples was decreased by $11 \%$ compared to HAD samples. This phenomenon can be explained by the thermal damage of free phenols occurred during the long time of drying in the case of HAD samples and by the thermo-mechanical effects of DIC treatment. Hung and Duy (2012) reported similar behavior in their study, when comparing the effect of drying methods on bioactive compounds in vegetables. They found that the free phenols in freeze-dried vegetables were significantly higher than those in hot air dried vegetables.

Table 3. Bioactive compounds evaluated in SD, HAD and FD strawberries

\begin{tabular}{|c|c|c|c|c|c|c|c|c|}
\hline Sample & $\begin{array}{c}\text { Pressure } \\
\text { (MPa) }\end{array}$ & $\begin{array}{c}\text { Time } \\
\text { (s) }\end{array}$ & TPC $^{a}$ & $F^{b}{ }^{b}$ & TAC $^{\mathrm{c}}$ & Cy-3-GI ${ }^{d}$ & Pe-3-Gl ${ }^{\mathrm{e}}$ & $\begin{array}{c}\% \text { ARA at } \\
250 \mu M\end{array}$ \\
\hline DIC1 & 0.60 & 20 & 17.14 & 4.15 & 4.96 & 0.60 & 0.92 & 43.20 \\
\hline DIC2 & 0.35 & 30 & 16.06 & 3.19 & 6.17 & 1.49 & 1.99 & 54.36 \\
\hline DIC3 & 0.35 & 20 & 14.58 & 2.93 & 6.26 & 1.66 & 2.29 & 54.27 \\
\hline DIC4 & 0.53 & 27 & 16.34 & 3.58 & 4.71 & 0.42 & 0.62 & 42.35 \\
\hline DIC5 & 0.53 & 13 & 16.67 & 3.28 & 5.71 & 1.12 & 1.73 & 45.85 \\
\hline DIC6 & 0.35 & 20 & 14.81 & 2.86 & 6.59 & 1.69 & 2.38 & 51.90 \\
\hline DIC7 & 0.17 & 13 & 13.97 & 2.79 & 5.98 & 2.55 & 3.35 & 49.87 \\
\hline DIC8 & 0.17 & 27 & 15.76 & 3.25 & 6.59 & 2.24 & 2.99 & 53.42 \\
\hline DIC9 & 0.10 & 20 & 14.60 & 2.70 & 5.76 & 2.49 & 3.68 & 49.68 \\
\hline DIC10 & 0.35 & 10 & 14.47 & 3.01 & 7.00 & 2.34 & 3.07 & 56.82 \\
\hline DIC11 & 0.35 & 20 & 16.35 & 3.06 & 5.96 & 1.78 & 2.43 & 53.61 \\
\hline HAD & & & 16.18 & 3.08 & 6.69 & 1.58 & 1.64 & 51.67 \\
\hline FD & & & 18.41 & 3.99 & 8.31 & 2.06 & 2.60 & 51.34 \\
\hline
\end{tabular}

\footnotetext{
${ }^{\mathrm{a}}$ Total phenolic content (mg eq. GA/g db);

${ }^{\text {b }}$ Flavonoid content (mg eq. Rutin/g db);

${ }^{\mathbf{c}}$ Total anthocyanin content (mg eq. Pe-3-Gl/g db);

${ }^{\mathrm{d}}$ Cyanidin-3-glucoside ( $\left.\mathrm{mg} / \mathrm{g} \mathrm{db}\right)$;

${ }^{\text {e }}$ Pelargonidin-3-glucoside (mg/g db).
}

In order to compare the operating parameters of DIC treatment, Figure $2(a, b)$ shows the effect of saturated steam pressure (MPa) and thermal holding time (s) on the TPC of SD samples. The highest value of TPC (17.14 $\mathrm{mg}$ eq.GA/g db) was verified for samples treated at $0.6 \mathrm{MPa}$ assaturated steam pressure for $20 \mathrm{~s}$. According to obtained results of DIC treatment, the saturated steam pressure had a significant and positive effect on the TPC compared to the thermal holding time. Hence, the higher the saturated steam pressure, the higher the TPC. This behavior is maybe due to the mechanical effect induced by the dropping pressure towards a vacuum, resulting in a broken-down the cell walls and thus the formation of some vacuoles and pores within the product thanks to water auto vaporization. Such new structures can increase the availability of the bound phenols and facilitate, subsequently, their extraction; while HAD and FD do not affect phenol-cell wall association (Hung \& Duy, 2012). Albitar et al. (2011) proved that, the increase in phenol availability is dependent not only on the DIC operating parameters, such as saturated steam pressure and processing time, but also the initial water content.

This result is not in contradiction with the previously found, when the different drying methods (HAD, FD and $\mathrm{SD})$ were compared because the DIC is a heat treatment (temperature and time couple treatment). Hence, some of these compounds, as free phenols, were destructed under sever conditions of high temperature treatment (high saturated steam pressure and longtime treatment) before broken-down the cell walls. 
The obtained regression model of TPC was as followswith $\mathrm{r}^{2}=82.7 \%$ :

$$
T P C=10.9115+5.81679 P+0.181985 t+10.526 P^{2}-0.420635 P t+0.000786558 t^{2}
$$
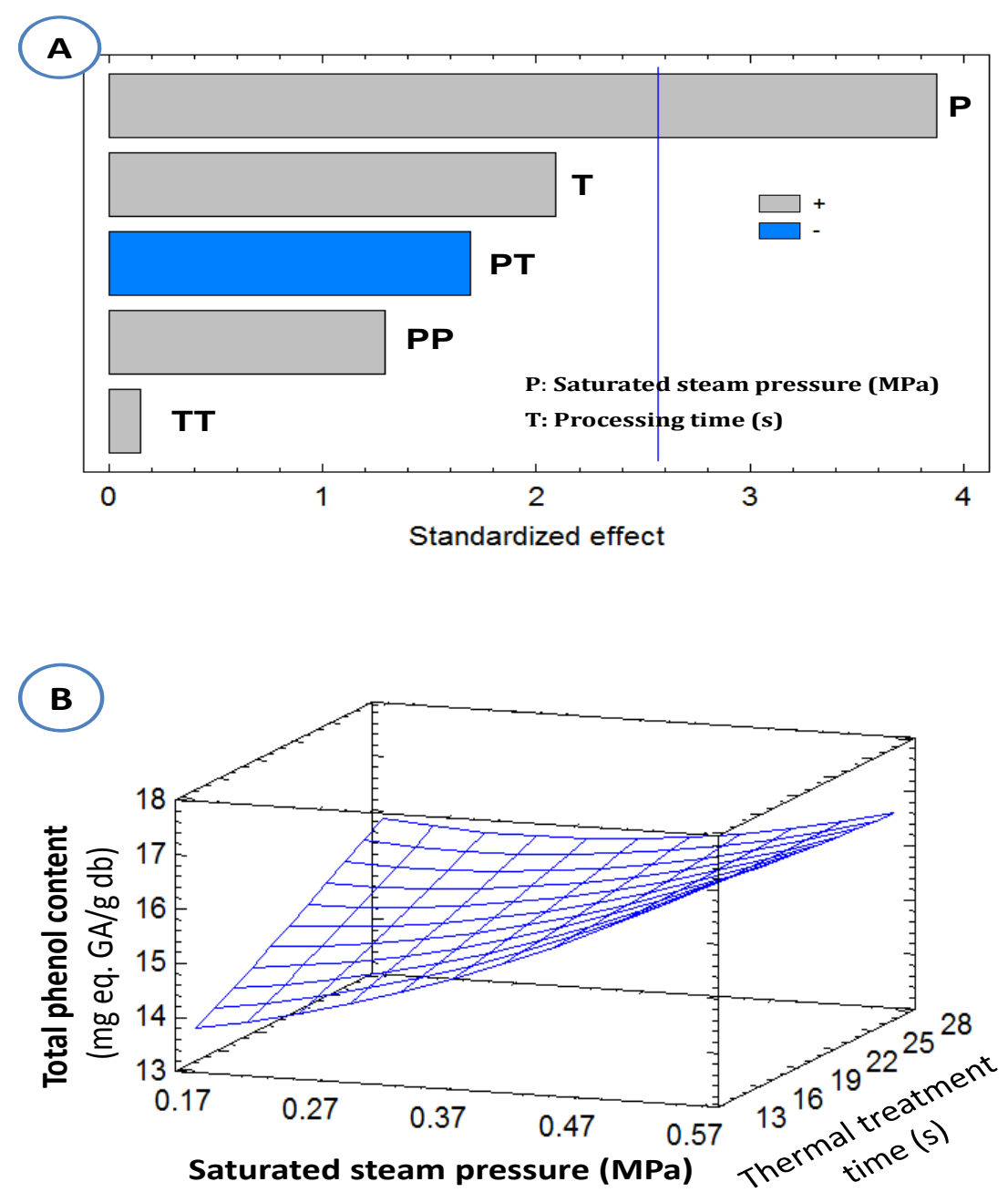

Figure 2. Effects of DIC operating parameters; pressure (MPa) and time (s) on the total phenols content (TPC; mg eq. GA/g db) of SD strawberries: A) Pareto Chart and B) Response Surface

\subsection{Flavonoid Content}

Total flavonoid content (FC) in hot air drying, freeze-drying and swell-drying is listed in Table 3. It was observed that thermal processes had a large influence in flavonoid availability, which depends on the magnitude and duration of drying processes. Flavonoid contents of HAD, FD and SD $(0.35 \mathrm{MPa}, 10 \mathrm{~s})$ strawberries were $3.08,3.99$ and $3.01 \mathrm{mg}$ eq. Rutin $/ \mathrm{g} \mathrm{db}$, respectively. There were not significant differences by these treatments with respect to the flavonoids content. However, the slight difference may be due to the thermal degradation of these compounds. Drying processes lead also to flavonoid degradation. The proportion lost depends on the drying method. Freeze-drying is the less aggressive method followed by hot air drying; while microwave and vacuum drying can have an intermediate degradation (Dong, Ma, Fu, \& Guo, 2011; Viña \& Chaves, 2008; Zainol, Abdul-Hamid, Bakar, \& Dek, 2009; Zhang, Hettiarachchy, Horax, Chen, \& Over, 2009).

The impact of DIC operating parameters (pressure and time) on FC is shown in Figure 3 (a, b). Similar behaviorin TPC was observed for FC. The saturated steam pressure had a significant effect on the FC compared to the thermal holding time. Hence, the higher the saturated steam pressure, the higher the flavonoid content. At saturated steam pressure of $0.6 \mathrm{MPa}$ during $20 \mathrm{~s}$, the highest value of FC (4.15 mg eq. Rutin/g db) was recorded for treated samples. 
The degradation of flavonoids not only depends on temperature and magnitude of heating; it may depend also on other parameters such as $\mathrm{pH}$, phytochemicals, structure and even the presence or absence of oxygen.

The thermal degradation of HAD products correlates with the drying time, due to the fact that shrinkage leads to decreasing diffusivity. DIC texturing can increase the diffusivity by opening the structure and possibly breaking cell walls. By reducing the drying time and releasing the bound flavonoids, the natural nutritive value dramatically improves as well as the availability of these compounds (Mounir, et al., 2011). As an example, Sabah Mounir et al. (2012) reported that the amount of quercetin in DIC-treated apple compared to untreated fresh samples was increased by up to $700 \%$. They obtained similar results with other fruits (e.g., cranberry fruits and seeds, sumac) and vegetables. Furthermore, results for onions proved that the instantaneity of the pressure drop toward a vacuum is an important factor influencing the availability of flavonoids (Mounir et al., 2011).
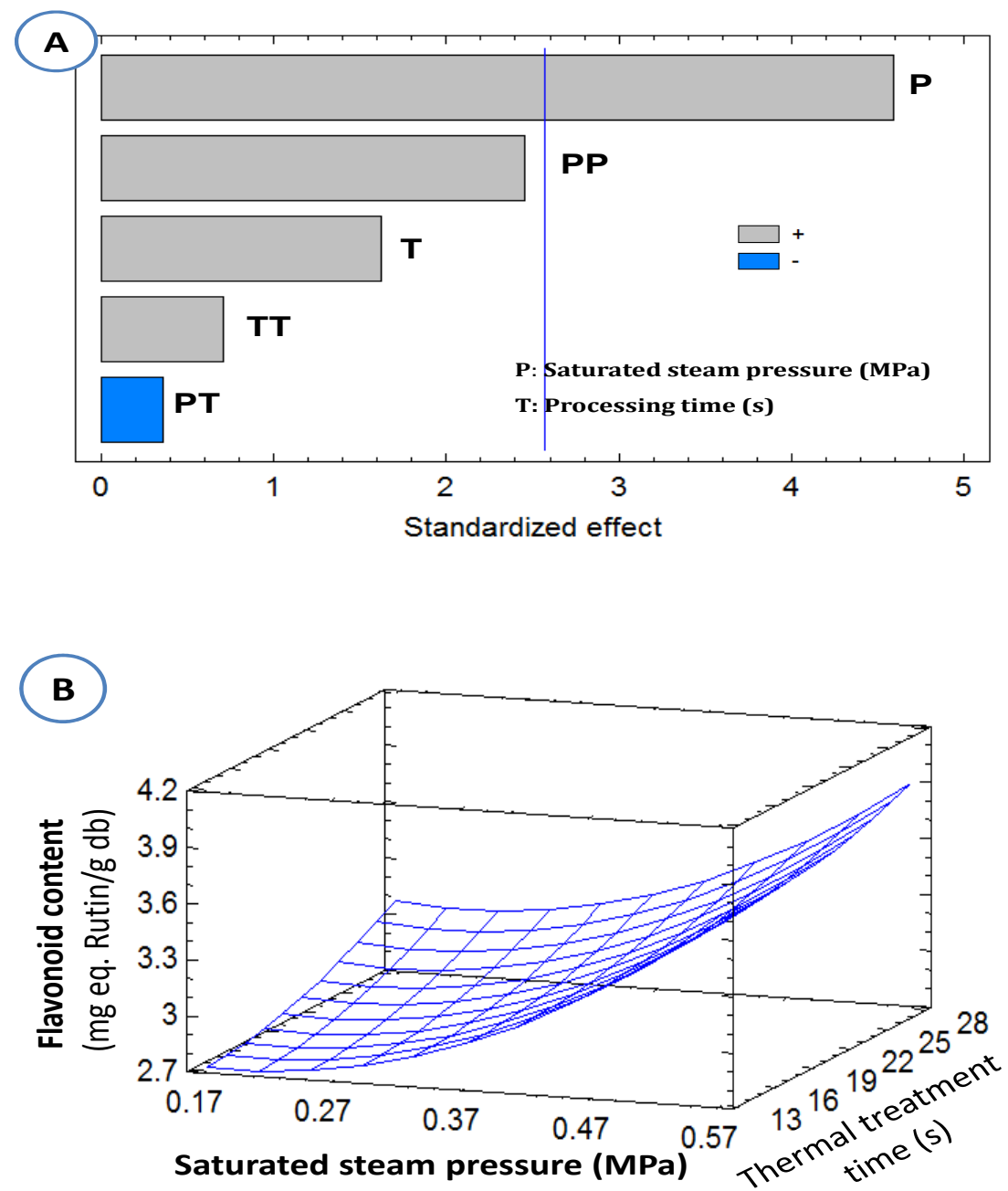

Figure 3. Effects of DIC operating parameters; pressure (MPa) and time (s) on the flavonoid content (FC; mg eq. Rutin/g db) of SD strawberries: A) Pareto Chart and B) Response Surface

The obtained regression model of FC was as follows with $\mathrm{r}^{2}=85.64 \%$ :

$$
F C=3.06594-2.30023 P-0.024343 t+7.0409 P^{2}-0.031746 P t+0.00133928 t^{2}
$$

\subsection{Total Anthocyanin Content}

The total anthocyanin content (TAC) in dried strawberry was investigated in several drying methods. As reported in Table 3, TAC was higher in the FD samples than HAD and SD samples by $19 \%$ and $16 \%$, respectively. A slight difference was observed in TAC between HAD and SD, an increase by $4 \%$ in TAC was reported in SD samples compared to HAD samples. 
DIC treatment at $0.35 \mathrm{MPa}$ of pressure for $10 \mathrm{~s}$, gave the highest value of TAC, 7.00 Pe-3-Gl/g db. Evaluating the effect of DIC operating parameters on the TAC in SD strawberries, Figure $4(\mathrm{a}, \mathrm{b})$ shows that the saturated steam pressure had a great influence compared to the thermal holding time. Thus, the higher the saturated steam pressure, the lower the TAC. The negative effect may be due to the thermal degradation of strawberries' anthocyanins. The highest values of TAC were found in SD samples treated at low pressure (under soft conditions). Ben Amor and Allaf (2009) reported that the yield of Total Monomeric Anthocyanin content (TMA) in dried Malaysian Roselle calyces was improved by up to $135 \%$ under soft conditions of $0.18 \mathrm{MPa}$ as saturated steam pressure during $18 \mathrm{~s}$.
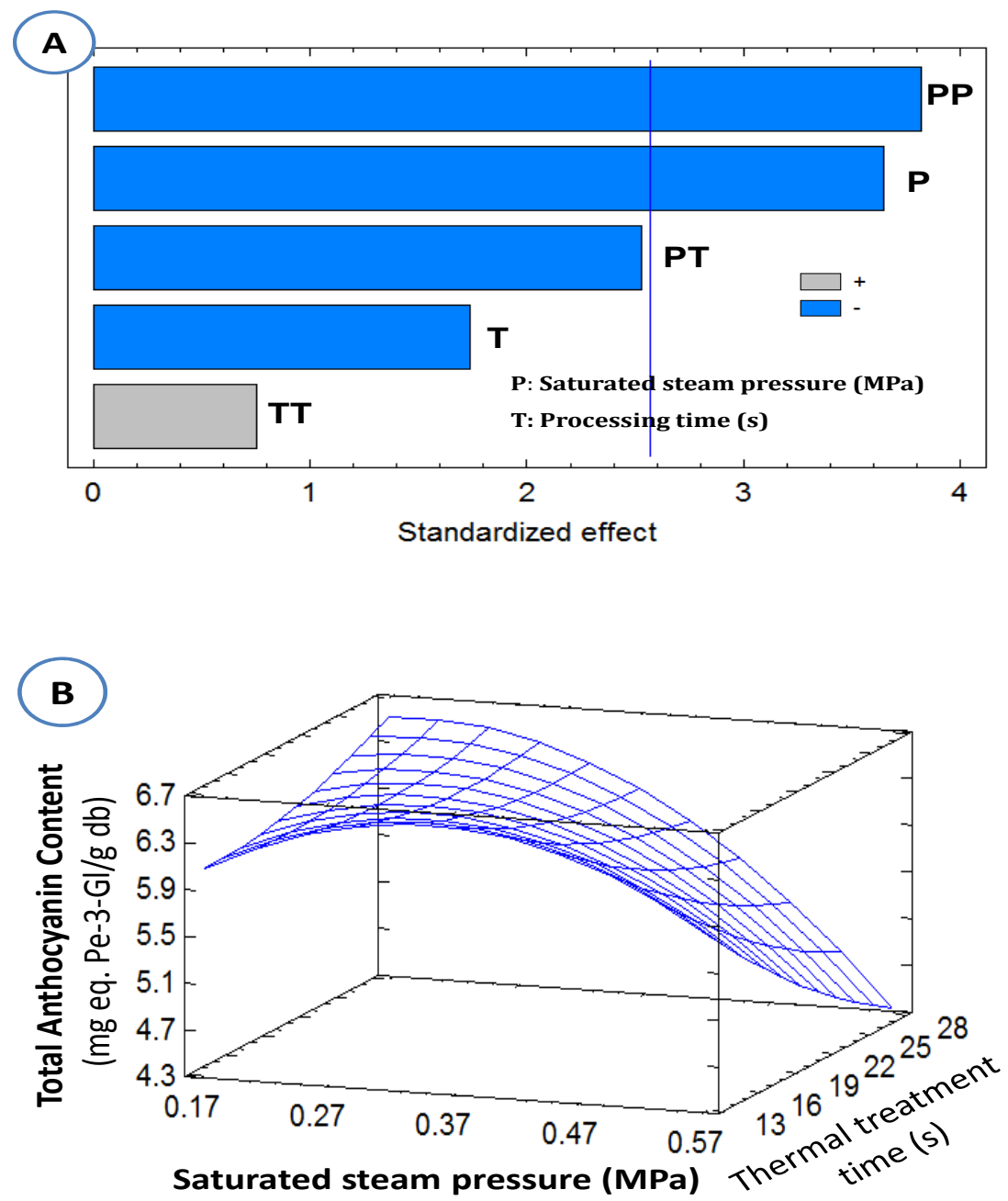

Figure 4. Effects of the saturated steam pressure (MPa) and the thermal treatment time of DIC on the total anthocyanin content (TAC; mg eq. Pe-3-Gl/g db) of SD strawberries. A) Pareto Chart and B) Response Surface

The obtained regression model for TAC, with $\mathrm{r}^{2}=89.17$, was:

$$
T A C=4.28351+15.1557 P+0.00122738 t-15.7794 P^{2}-0.319444 P t+0.0020663 t^{2}
$$

The principal anthocyanins in strawberries are pelargonidin-3-glucoside (Pe-3-Gl) and cyanidin-3-glucoside (Cy-3-Gl) (da Silva, Escribano-Bailón, Pérez Alonso, Rivas-Gonzalo, \& Santos-Buelga, 2007; Giampieri et al., 2012). Pelargonidin-3-glucoside is the major anthocyanin in strawberries independent from genetic and environmental factors and the presence of cyanidin-3-glucoside seems to be constant and in less quantity (Giampieri et al., 2012; Patras, Brunton, Da Pieve, \& Butler, 2009).

Anthocyanins were quantified by HPCL using Cy-3-Gl and Pe-3-Gl standards. The levels of Cy-3-Gl and Pe-3-Glare listed in Table 3. It was found that SD strawberries samples had the highest levels of Cy-3-Gl and Pe-3-GIcompared to HAD and FD. The levels of Cy-3-Gl and Pe-3-GI in SD samples were increased by 32\% and $11 \%$, and by $47 \%$ and $15 \%$; both compared to HAD and FD samples, respectively. The highest level of these 
anthocyanin types was obtained at DIC texturing parameters of $0.35 \mathrm{MPa}$ and $0.10 \mathrm{MPa}$ as saturated steam pressure for $10 \mathrm{~s}$ and $20 \mathrm{~s}$ as thermal holding time, respectively.

Although, the highest levels of Cy-3-Gl and Pe-3-Gl were obtained in SD strawberry samples, the saturated steam pressure had a significant effect on strawberry's content of these compounds compared to the thermal holding time. The higher the saturated steam pressure, the lower the levels of Cy-3-Gl (Figures 5a and 5b) and Pe-3-Gl (Figure 6a and 6b). This phenomenon can be explained by the thermal destruction of these compounds as a result of increasing the saturated steam pressure during the treatment. Therefore, the highest levels were obtained under soft conditions (low saturated steam pressure and short time treatment) as early mentioned.
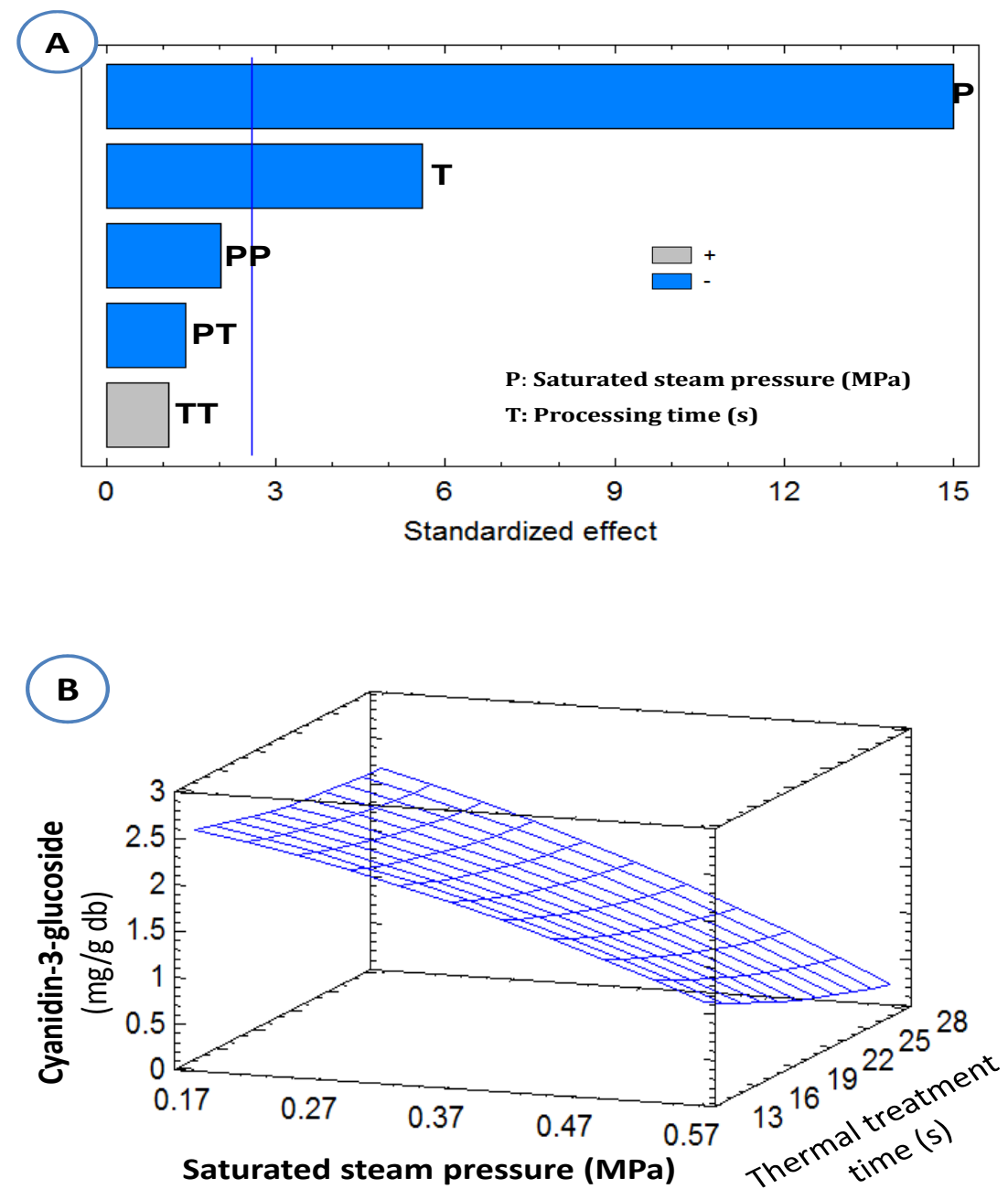

Figure 5. Effects of DIC operating parameters (pressure; MPa and time; s) on the cyanidin-3-glucoside (Cy-3-Gl; $\mathrm{mg} / \mathrm{g} \mathrm{db}$ )of SD strawberries. A) Pareto Chartand B) Response Surface

The obtained regression model for Cy-3-Gl was as follows with $\mathrm{r}^{2}=98.15$ :

$$
C y-3-G l=3.48232+0.01362 P-0.0659896 t-3.68443 P^{2}-0.07738 P t+0.0013393 t^{2}
$$



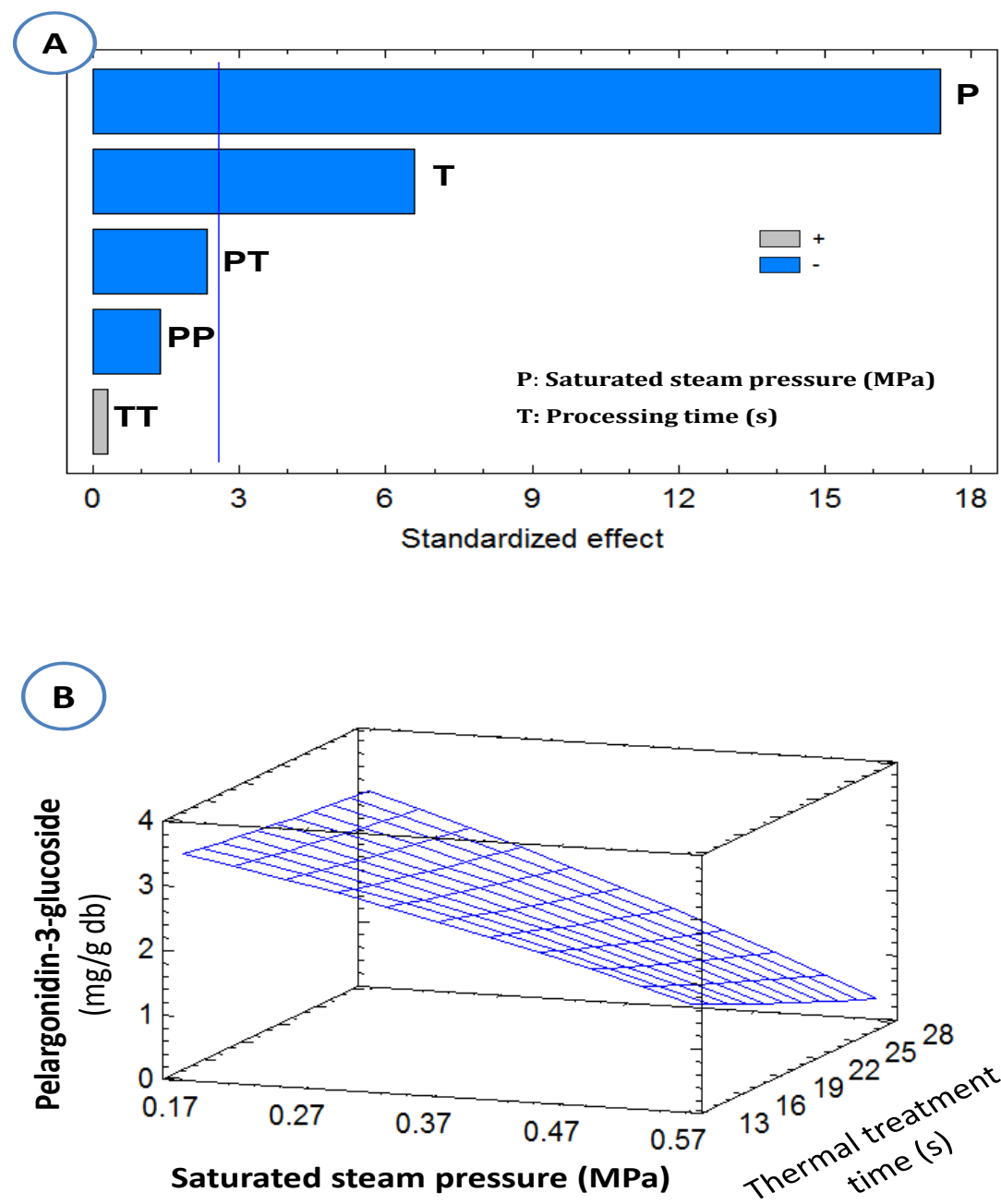

Figure 6. Effects of DIC parameters (saturated steam pressure; MPa and thermal treatment time; s) on thepelargonidin-3-glucoside (Pe-3-Gl; mg/g db) of SD strawberries. A) Pareto Chart and B) Response Surface

The obtained regression model for Pe-3-Gl was as followswith $\mathrm{r}^{2}=98.60$ :

$$
P e-3-G l=4.1305-0.475243 P-0.0186178 t-2.8997 P^{2}+0.14881 P t+0.00042943 t^{2}
$$

\subsection{Antioxidant Capacity}

The antioxidant capacity of fruits is closely correlated to the presence of efficient oxygen radical scavengers, such as vitamin $\mathrm{C}$ and phenolic compounds (Giampieri et al., 2012). Strawberries have a greater antioxidant capacity (2 to 11-fold) than apples, peaches, pears, grapes, tomatoes, oranges, or kiwifruit (Giampieri et al., 2012; Scalzo, Politi, Pellegrini, Mezzetti, \& Battino, 2005; Wang, Cao, \& Prior, 1996). In the present study, scavenging capacity was evaluated as percent discoloration of a free radical DPPH solution and expressed as antiradical activity ( $\%$ ARA). The concentration tested for the different extracts in this essay was $250 \mu \mathrm{M}(\mu \mathrm{M}$ equivalent of Gallic acid).

As shown in Table 3, there was no significant difference in \% ARA of HAD and FD samples. Whereas, it is increased by $9 \%$ and $10 \%$ in SD samples $(56.82 \%)$ compared to HAD $(51.67 \%)$ and FD $(51.34 \%)$ samples respectively.

The effect of saturated steam pressure and thermal holding time on \% ARA was illustrated in Figure $7(a, b)$. The saturated steam pressure had a negative effect on the \% ARA; it means that in SD samples, the higher the saturated steam pressure, the lower the \% ARA. However, the highest \% ARA was found in SD strawberries samples treated under the softest conditions (lowest saturated steam pressure for shortest time treatment). For example, the highest level of \% ARA was found at $56.82 \%$ for SD samples treated at $0.35 \mathrm{MPa}$ for $10 \mathrm{~s}$. 

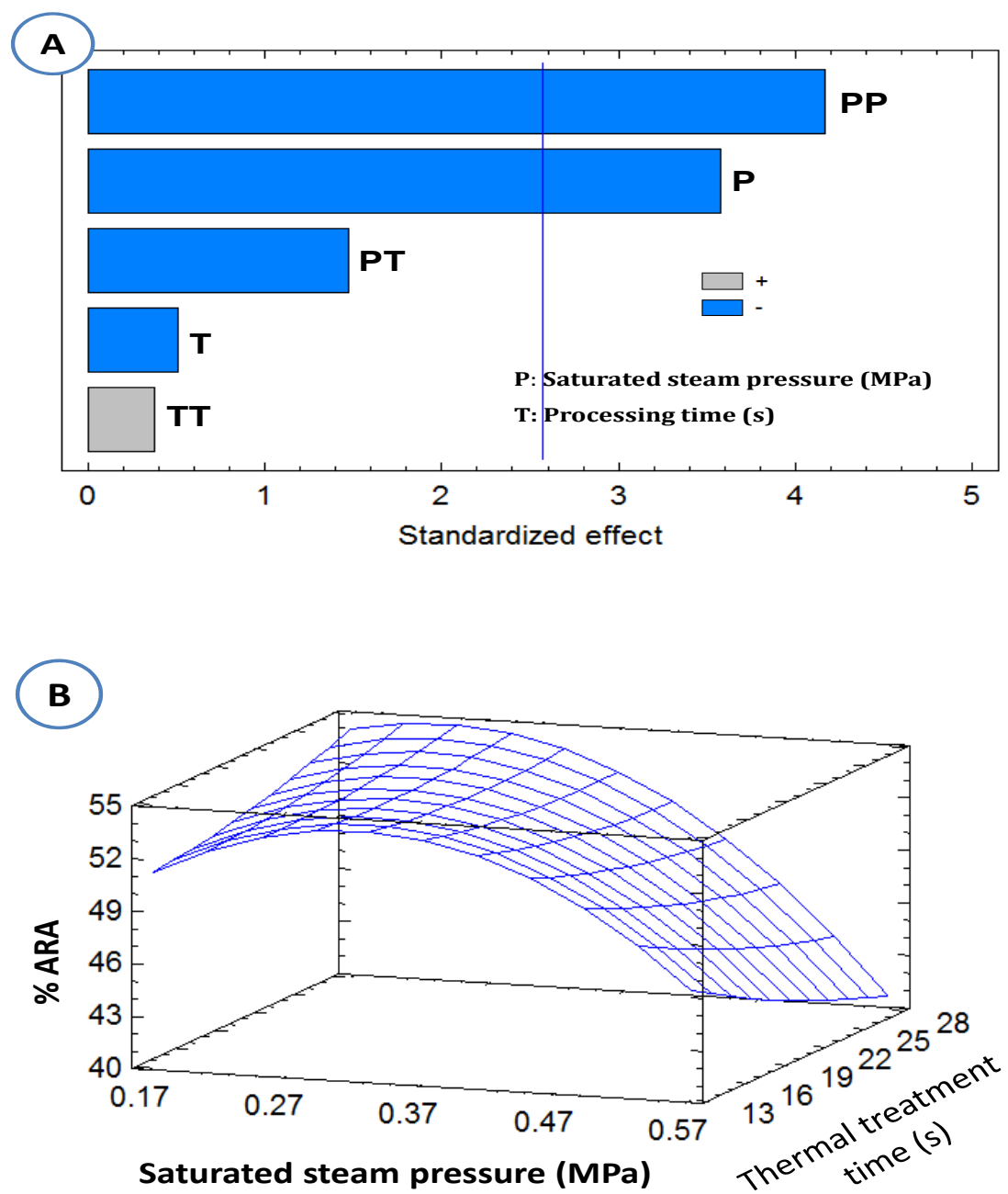

Figure 7. Effects of DIC operating parameters; pressure (MPa) and time (s) on the antioxidant activity (\% ARA) of SD strawberries: A) Pareto Chart and B) Response Surface

It is difficult to explain the evolution of the antioxidant activity according to heat process conditions. Too numerous factors are implied in its evolution. A decrease in phenolic content does not lead systematically to a decrease of the antioxidant activity. Indeed, with lower phenolic content, one can also have a higher antioxidant activity (Buchner, Krumbein, Rohn, \& Kroh, 2006; Murakami, Yamaguchi, Takamura, \& Atoba, 2004). Thus, an increase of antioxidant activity is noticed in many studies using thermal processes (Chandrasekara \& Shahidi, 2011; Hartmann, Patz, Andlauer, Dietrich, \& Ludwig, 2008; Sharma \& Gujral, 2011). However, interactions are important phenomena, which act on the antioxidant activity of molecules. Depending on this environment, synergies between antioxidant compounds and the food matrix can occur (Wang, Meckling, Marcone, Kakuda, \& Tsao, 2011). In some cases, the antioxidant capacity of flavonoids in a food matrix is enhanced (Freeman, Eggett, \& Parker, 2010); while in others, this antioxidant activity is reduced (Davidov-Pardo, Arozarena, \& Marín-Arroyo, 2011; Hidalgo, Sánchez-Moreno, \& de Pascual-Teresa, 2010), or it remains constant (Leitao et al., 2011).

The obtained regression model for the antioxidant capacity was as followed with $\mathrm{r}^{2}=87.61$ :

$$
\% A R A=37.8219+101.779 P+0.118656 t-129.495 P^{2}-1.3988 P t+0.00774239 t^{2}
$$

\subsection{Correlation between DPPH Radical Scavenging and TPC, FC and TAC in Swell-Dried Strawberries}

The highest correlation was found between TAC and DPPH scavenging in swell-dried strawberrieswith $\mathrm{r}^{2}=$ 0.8337 (Figure 8). While, the correlations between DPPH scavenging and FC and TFC were observed with $\mathrm{r}^{2}=$ 0.4129 and 0.2956 , respectively. 


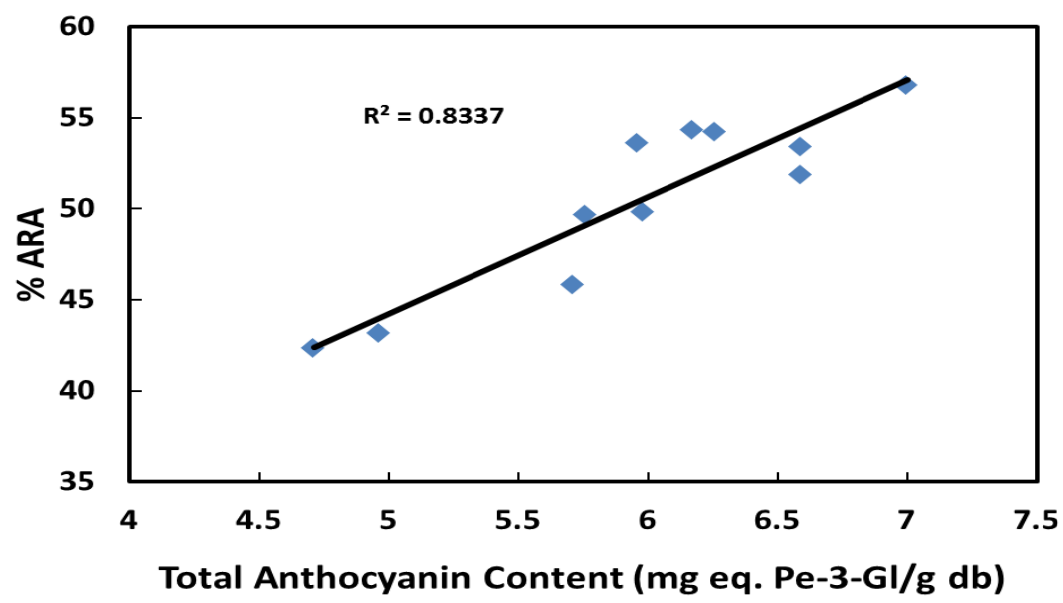

Figure 8. Correlation between DPPH radical scavenging and TAC in swell dried strawberries

These results indicatedthat antioxidant capacitywas strongly correlated to TCA (Figure 8) and not correlated to FCand TFCin SD strawberry samples. Therefore, these results are in agreement with those obtained by Andersen et al. (2004). These authors reported that the antioxidant activity of strawberries was directly correlated with anthocyanin content in the fruit.

\section{Conclusions}

As a general tendency, these results show that swell-drying technique can be considered as an alternative of drying method for fragile fruits, such as strawberries. Mainly because SD method helps to reduce the time of drying (Alonzo-Macías et al., 2012) and, subsequently, decreases the consumed energy and drying costs compared to classical hot air drying and freeze-drying. Additionally, SD globally preserves the nutritional value and bioactive molecules and increases the availability of these compounds. It was demonstrated that at optimal DIC conditions (0.35 MPa assaturated steam pressure for $10 \mathrm{~s}) \mathrm{SD}$ strawberries were richer in anthocyanins, phenolic compounds and flavonoids compared with the other drying methods. A strong correlation between antioxidant activity and total anthocyanin content was established in SD strawberries.

Thus, DIC is a flexible operation that can be optimized to meet the consumer and industry's needs.

\section{Acknowledgment}

The authors wish to thank CONACYT and Institut Français-Egypte for their financial support; and ABCAR-DIC Process for technical contribution.

\section{References}

Abdel-Aal, E. S. M., \& Hucl, P. (1999). A Rapid Method for Quantifying Total Anthocyanins in Blue Aleurone and Purple Pericarp Wheats. Cereal Chemistry Journal, 76(3), 350-354. http://dx.doi.org/10.1094/CCHEM.1999.76.3.350

Albitar, N., Mounir, S., Besombes, C., \& Allaf, K. (2011). Improving the Drying of Onion Using the Instant Controlled Pressure Drop Technology. Drying Technology, 29(9), 993-1001. http://dx.doi.org/10.1080/07373937.2010.507912

Alonzo-Macías, M., Mounir, S., Cardador-Martínez, A., Montejano-Gaitán, J. G., \& Allaf, K. (2012). Comparative Study of Various Drying Processes at Physical and Chemical Properties of Strawberries $\begin{array}{lllll}\text { (Fragaria var. Camarosa). Procedia 267-282. } & \text { Engineering, }\end{array}$ http://dx.doi.org/10.1016/j.proeng.2012.07.418

Andersen, Ø. M., Fossen, T., Torskangerpoll, K., Fossen, A., \& Hauge, U. (2004). Anthocyanin from strawberry (Fragaria ananassa) with the novel aglycone, 5-carboxypyranopelargonidin. Phytochemistry, 65(4), 405-410. http://dx.doi.org/10.1016/j.phytochem.2003.10.014

Basu, A., Wilkinson, M., Penugonda, K., Simmons, B., Betts, N., \& Lyons, T. (2009). Freeze-dried strawberry powder improves lipid profile and lipid peroxidation in women with metabolic syndrome: baseline and post intervention effects. Nutrition Journal, 8(1), 1-7. http://dx.doi.org/10.1186/1475-2891-8-43 
Ben Amor, B., \& Allaf, K. (2009). Impact of texturing using instant pressure drop treatment prior to solvent extraction of anthocyanins from Malaysian Roselle (Hibiscus sabdariffa). Food Chemistry, 115(3), 820-825. http://dx.doi.org/10.1016/j.foodchem.2008.12.094

Blanda, G., Cerretani, L., Cardinali, A., Barbieri, S., Bendini, A., \& Lercker, G. (2009). Osmotic dehydrofreezing of strawberries: Polyphenolic content, volatile profile and consumer acceptance. LWT-Food Science and Technology, 42(1), 30-36. http://dx.doi.org/10.1016/j.lwt.2008.07.002

Böhm, H. (1994). G. Mazza und E. Miniati: Anthocyanins in Fruits, Vegetables and Grains. 362 Seiten, zahlr. Abb. und Tab. CRC Press, Boca Raton, Ann Arbor, London, Tokyo 1993. Preis: 144. Food / Nahrung, 38(3), 343-343. http://dx.doi.org/10.1002/food.19940380317

Buchner, N., Krumbein, A., Rohn, S., \& Kroh, L. W. (2006). Effect of thermal processing on the flavonols rutin and quercetin. Rapid Communications in Mass Spectrometry, 20(21), 3229-3235. http://dx.doi.org/10.1002/rcm.2720

Burda, S., \& Oleszek, W. (2001). Antioxidant and Antiradical Activities of Flavonoids. Journal of Agricultural and Food Chemistry, 49(6), 2774-2779. http://dx.doi.org/10.1021/jf001413m

Chandrasekara, N., \& Shahidi, F. (2011). Effect of Roasting on Phenolic Content and Antioxidant Activities of Whole Cashew Nuts, Kernels, and Testa. Journal of Agricultural and Food Chemistry, 59(9), 5006-5014. http://dx.doi.org/10.1021/jf2000772

Crecente-Campo, J., Nunes-Damaceno, M., Romero-Rodríguez, M. A., \& Vázquez-Odériz, M. L. (2012). Color, anthocyanin pigment, ascorbic acid and total phenolic compound determination in organic versus conventional strawberries (Fragaria x ananassa Duch, cv Selva). Journal of Food Composition and Analysis. http://dx.doi.org/10.1016/j.jfca.2012.07.004

da Silva, F. L., Escribano-Bailón, M. T., Pérez Alonso, J. J., Rivas-Gonzalo, J. C., \& Santos-Buelga, C. (2007). Anthocyanin pigments in strawberry. LWT-Food Science and Technology, 40(2), 374-382. http://dx.doi.org/10.1016/j.lwt.2005.09.018

Davidov-Pardo, G., Arozarena, I., \& Marín-Arroyo, M. (2011). Stability of polyphenolic extracts from grape seeds after thermal treatments. European Food Research and Technology, 232(2), 211-220. http://dx.doi.org/10.1007/s00217-010-1377-5

Dong, J., Ma, X., Fu, Z., \& Guo, Y. (2011). Effects of microwave drying on the contents of functional constituents of Eucommia ulmoides flower tea. Industrial Crops and Products, 34(1), 1102-1110. http://dx.doi.org/10.1016/j.indcrop.2011.03.026

Freeman, B. L., Eggett, D. L., \& Parker, T. L. (2010). Synergistic and Antagonistic Interactions of Phenolic Compounds Found in Navel Oranges. Journal of Food Science, 75(6), C570-C576. http://dx.doi.org/10.1111/j.1750-3841.2010.01717.x

Giampieri, F., Tulipani, S., Alvarez-Suarez, J. M., Quiles, J. L., Mezzetti, B., \& Battino, M. (2012). The strawberry: Composition, nutritional quality, and impact on human health. Nutrition, 28(1), 9-19. http://dx.doi.org/10.1016/j.nut.2011.08.009

Haddad, J., \& Allaf, K. (2007). A study of the impact of instantaneous controlled pressure drop on the trypsin inhibitors of soybean. Journal of Food Engineering, 79(1), 353-357. http://dx.doi.org/10.1016/j.jfoodeng.2006.01.066

Hannum, S. M. (2004). Potential Impact of Strawberries on Human Health: A Review of the Science. Critical Reviews in Food Science and Nutrition, 44(1), 1-17. http://dx.doi.org/10.1080/10408690490263756

Hartmann, A., Patz, C.-D., Andlauer, W., Dietrich, H., \& Ludwig, M. (2008). Influence of Processing on Quality Parameters of Strawberries. Journal of Agricultural and Food Chemistry, 56(20), 9484-9489. http://dx.doi.org/10.1021/jf801555q

Hidalgo, M., Sánchez-Moreno, C., \& de Pascual-Teresa, S. (2010). Flavonoid-flavonoid interaction and its effect on their antioxidant activity. Food Chemistry, 121(3), 691-696. http://dx.doi.org/10.1016/j.foodchem.2009.12.097

Hung, P. V., \& Duy, T. L. (2012). Effects of drying methods on bioactive compounds of vegetables and correlation between bioactive compounds and their antioxidants. International Food Research Journal, 19(1), 327-332. 
Kamal, I. M., Sobolik, V., Kristiawan, M., Mounir, S. M., \& Allaf, K. (2008). Structure expansion of green coffee beans using instantaneous controlled pressure drop process. Innovative Food Science \& Amp; Emerging Technologies, 9(4), 534-541. http://dx.doi.org/10.1016/j.ifset.2008.01.004

Karathanos, V. T. (1999). Determination of water content of dried fruits by drying kinetics. Journal of Food Engineering, 39(4), 337-344. http://dx.doi.org/10.1016/s0260-8774(98)00132-0

Leitao, C. L., Marchioni, E., Bergaentzlé, M., Zhao, M., Didierjean, L., Taidi, B., \& Ennahar, S. D. (2011). Effects of Processing Steps on the Phenolic Content and Antioxidant Activity of Beer. Journal of Agricultural and Food Chemistry, 59(4), 1249-1255. http://dx.doi.org/10.1021/jf104094c

Louka, N., \& Allaf, K. (2004). Expansion ratio and color improvement of dried vegetables texturized by a new process "Controlled Sudden Decompression to the vacuum": Application to potatoes, carrots and onions. Journal of Food Engineering, 65(2), 233-243. http://dx.doi.org/10.1016/j.jfoodeng.2004.01.020

Modise, D. M. (2008). Does freezing and thawing affect the volatile profile of strawberry fruit (Fragaria $\mathrm{x}$ ananassa Duch.)? Postharvest Biology and Technology, 50(1), 25-30. http://dx.doi.org/10.1016/j.postharvbio.2008.03.009

Mounir, S., Allaf, T., Mujumdar, A. S., \& Allaf, K. (2012). Swell Drying: Coupling Instant Controlled Pressure Drop DIC to Standard Convection Drying Processes to Intensify Transfer Phenomena and Improve $\begin{array}{lllll}\text { Quality-An } \quad \text { Overview. } & \text { Drying } & \text { Technology, } & 30(14), & 1508-1531 .\end{array}$ http://dx.doi.org/10.1080/07373937.2012.693145

Mounir, S., Besombes, C., Al-Bitar, N., \& Allaf, K. (2011). Study of Instant Controlled Pressure Drop DIC Treatment in Manufacturing Snack and Expanded Granule Powder of Apple and Onion. Drying Technology, 29(3), 331-341. http://dx.doi.org/10.1080/07373937.2010.491585

Murakami, M., Yamaguchi, T., Takamura, H., \& Atoba, T. M. (2004). Effects of Thermal Treatment on Radical-scavenging Activity of Single and Mixed Polyphenolic Compounds. Journal of Food Science, 69(1), FCT7-FCT10. http://dx.doi.org/10.1111/j.1365-2621.2004.tb17848.x

Olsson, M. E., Ekvall, J., Gustavsson, K.-E., Nilsson, J., Pillai, D., Sjöholm, I., .. Nyman, M. G. L. (2004). Antioxidants, Low Molecular Weight Carbohydrates, and Total Antioxidant Capacity in Strawberries (Fragaria $\times$ ananassa): Effects of Cultivar, Ripening, and Storage. Journal of Agricultural and Food Chemistry, 52(9), 2490-2498. http://dx.doi.org/10.1021/jf030461e

Oomah, B. D., Cardador-Martínez, A., \& Loarca-Piña, G. (2005). Phenolics and antioxidative activities in common beans (Phaseolus vulgaris L). Journal of the Science of Food and Agriculture, 85(6), 935-942. http://dx.doi.org/10.1002/jsfa.2019

Oszmiański, J., Wojdyło, A., \& Kolniak, J. (2009). Effect of 1-ascorbic acid, sugar, pectin and freeze-thaw treatment on polyphenol content of frozen strawberries. LWT - Food Science and Technology, 42(2), 581-586. http://dx.doi.org/10.1016/j.lwt.2008.07.009

Panico, A. M., Garufi, F., Nitto, S., Di Mauro, R., Longhitano, R. C., Magrì, G., ... De Guidi, G. (2009). Antioxidant activity and phenolic content of strawberry genotypes from Fragaria $\mathrm{x}$ ananassa. Pharmaceutical Biology, 47(3), 203-208. http://dx.doi.org/10.1080/13880200802462337

Patras, A., Brunton, N. P., Da Pieve, S., \& Butler, F. (2009). Impact of high pressure processing on total antioxidant activity, phenolic, ascorbic acid, anthocyanin content and colour of strawberry and blackberry purées. Innovative Food Science \&amp; Emerging Technologies, 10(3), 308-313. http://dx.doi.org/10.1016/j.ifset.2008.12.004

Ratti, C. (2001). Hot air and freeze-drying of high-value foods: a review. Journal of Food Engineering, 49(4), 311-319. http://dx.doi.org/10.1016/S0260-8774(00)00228-4

Scalzo, J., Politi, A., Pellegrini, N., Mezzetti, B., \& Battino, M. (2005). Plant genotype affects total antioxidant capacity and phenolic contents in fruit. Nutrition, 21(2), 207-213. http://dx.doi.org/10.1016/j.nut.2004.03.025

Sharma, P., \& Gujral, H. S. (2011). Effect of sand roasting and microwave cooking on antioxidant activity of barley. Food Research International, 44(1), 235-240. http://dx.doi.org/10.1016/j.foodres.2010.10.030

Singleton, V. L., Orthofer, R., \& Lamuela-Raventós, R. M. (1999). Analysis of total phenols and other oxidation substrates and antioxidants by means of folin-ciocalteu reagent. In P. Lester (Ed.), Methods in Enzymology (vol. 299, pp. 152-178). Academic Press. 
Viña, S. Z., \& Chaves, A. R. (2008). Effect of heat treatment and refrigerated storage on antioxidant properties of pre-cut celery (Apium graveolens L.). International Journal of Food Science \& Technology, 43(1), 44-51. http://dx.doi.org/10.1111/j.1365-2621.2006.01380.x

Wang, H., Cao, G., \& Prior, R. L. (1996). Total Antioxidant Capacity of Fruits. Journal of Agricultural and Food Chemistry, 44(3), 701-705. http://dx.doi.org/10.1021/jf950579y

Wang, S., Meckling, K. A., Marcone, M. F., Kakuda, Y., \& Tsao, R. (2011). Synergistic, Additive, and Antagonistic Effects of Food Mixtures on Total Antioxidant Capacities. Journal of Agricultural and Food Chemistry, 59(3), 960-968. http://dx.doi.org/10.1021/jf1040977

Zainol, M. M., Abdul-Hamid, A., Bakar, F. A., \& Dek, S. P. (2009). Effect of different drying methods on the degradation of selected flavonoids in Centella asiatica. International Food Research Journal, 16(4), 531-537.

Zhang, M., Hettiarachchy, N. S., Horax, R., Chen, P., \& Over, K. F. (2009). Effect of Maturity Stages and Drying Methods on the Retention of Selected Nutrients and Phytochemicals in Bitter Melon (Momordica charantia) Leaf. Journal of Food Science, 74(6), C441-C448. http://dx.doi.org/10.1111/j.1750-3841.2009.01222.x 